\title{
Wideband Channel Model for Aeronautical Telemetry
}

\author{
Christian Bettweiser
}

Adam Davis

Michael D. Rice

mdr@byu.edu

Follow this and additional works at: https://scholarsarchive.byu.edu/facpub

Part of the Electrical and Computer Engineering Commons

\section{Original Publication Citation}

Michael Rice, Adam Davis, and Christian Bettweiser, "A Wideband Channel Model for

Aeronautical Telemetry" IEEE Transactions on Aerospace and Electronic Systems, vol 4, issue 1, pp. 57-69, January 24

\section{BYU ScholarsArchive Citation}

Bettweiser, Christian; Davis, Adam; and Rice, Michael D., "Wideband Channel Model for Aeronautical Telemetry" (2004). Faculty Publications. 461.

https://scholarsarchive.byu.edu/facpub/461

This Peer-Reviewed Article is brought to you for free and open access by BYU ScholarsArchive. It has been accepted for inclusion in Faculty Publications by an authorized administrator of BYU ScholarsArchive. For more information, please contact ellen_amatangelo@byu.edu. 


\section{Wideband Channel Model for Aeronautical Telemetry}

\author{
MICHAEL RICE, Senior Member, IEEE \\ ADAM DAVIS \\ CHRISTIAN BETTWEISER \\ Brigham Young University
}

A multipath channel model for wideband aeronautical telemetry links is presented. Channel sounding data were collected at Edwards AFB, CA, at both L-band and lower S-band. Frequency domain analysis techniques were used to evaluate candidate channel models. The channel model is composed of three propagation paths: a line-of-sight direct path and two specular reflections. The first specular reflection is characterized by a relative amplitude of $70 \%$ to $96 \%$ of the line-of-sight amplitude and a delay of 10-80 ns. This path is the result of "ground bounces" off the dry lake bed at Edwards and is a typical terrain feature at DoD test ranges located in the western United States. The amplitude and delay of this path are defined completely by the flight path geometry. The second path has a much lower amplitude and a longer delay. The gain of this path is well modeled as a zero-mean complex Gaussian random variable. The relative amplitude is approximately $2 \%$ to $8 \%$ of the line-of-sight amplitude. The mean excess delay is $155 \mathrm{~ns}$ with an rms delay spread of 74 ns.

Manuscript received March 20, 2002; revised September 23, 2002; released for publication September 23, 2003.

IEEE Log No. T-AES/40/1/826454.

Refereeing of this contribution was handled by T. F. Roome.

This work was supported under a grant from the Air Force ARTM program (Contracts F04700-02-P-0080 and F04700-02-P-0081).

Authors' address: Dept. of Electrical and Computer Engineering, 459 Clyde Building, Brigham Young University, Provo, UT 84602, E-mail: (mdr@ee.byu.edu).

0018-9251/04/\$17.00 (c) 2004 IEEE

\section{INTRODUCTION}

Channel models are important for assessing the performance of modulation, equalization, and coding techniques on real channels. Channel models are usually categorized as either "narrowband" or "wideband." Narrowband channel models are appropriate for situations where the signal bandwidth is much less than the coherence bandwidth of the multipath fading process [1, ch. 14]. In this case, the individual multipath reflections are not resolvable in the signal bandwidth. The resulting channel models are usually multiplicative fading models where a statistical description of the time-varying attenuation is the central focus of the model [2]. Examples of narrowband fading models include the Rayleigh fading channel commonly used for urban cellular channels [2], the Rice fading channel commonly used for modeling land-mobile satellite channels [3, 4], and a narrowband channel model for aeronautical telemetry [5].

Wideband channel models are used in those situations where the signal bandwidth is on the order of or larger than the coherence bandwidth of the multipath fading process. In this case, the individual multipath reflections are resolvable in the signal bandwidth. In this case the channel is modeled as a tapped delay line with time-varying coefficients to account for changes in the characteristics of the multipath. If the channel variations are slow enough, then over a short time interval, the channel can be modeled as a linear, time-invariant system whose complex baseband impulse response is composed of $L$ propagation paths and is of the form

$$
\tilde{h}(t)=\sum_{k=0}^{L-1} \tilde{\Gamma}_{k} \exp \left\{-j \omega_{c} \tilde{\tau}_{k}\right\} \delta\left(t-\tilde{\tau}_{k}\right)
$$

where $\tilde{\Gamma}_{k}$ is the complex gain of the $k$ th propagation path, $\tilde{\tau}_{k}$ is the propagation delay of the $k$ th propagation path, and $\omega_{c}$ is the RF carrier frequency. We label path 0 the line-of-sight path and normalize the other path gains and delays to the line-of-sight path using

$$
\begin{aligned}
h(t) & =\frac{\tilde{h}\left(t+\tilde{\tau}_{0}\right)}{\tilde{\Gamma}_{0}} \\
& =\delta(t)+\sum_{k=1}^{L-1} \frac{\tilde{\Gamma}_{k}}{\tilde{\Gamma}_{0}} \exp \left\{-j \omega_{c}\left(\tilde{\tau}_{k}-\tilde{\tau}_{0}\right)\right\} \delta\left(t-\tilde{\tau}_{k}+\tilde{\tau}_{0}\right) \\
& =\delta(t)+\sum_{k=1}^{L-1} \Gamma_{k} \exp \left\{-j \omega_{c} \tau_{k}\right\} \delta\left(t-\tau_{k}\right)
\end{aligned}
$$

where $\Gamma_{k}$ and $\tau_{k}$ are defined implicitly in (3). A simple 2-ray model $(L=2)$ based on a single ground reflection has proven to be a useful propagation model for predicting large-scale signal strength for systems 
that use tall towers and for line-of-sight microcell channels in urban environments [6]. Rummler's model [7] is a 3-ray $(L=3)$ model that is a good model for the $6 \mathrm{GHz}$ terrestrial microwave line-of-sight channel. In the work presented here, we show that $L=3$ yields an accurate model for the multipath observed in aeronautical telemetry applications. In addition, we provide models which accurately predict the values of the complex gains and delays for the two reflected propagation paths.

\section{CHANNEL SOUNDING EXPERIMENTS}

\section{A. Experimental Configuration}

The experimental configuration for the channel sounding experiments is illustrated in Fig. 1. A length-127 PN sequence ${ }^{1}$ was transmitted using a $10 \mathrm{Mbit} / \mathrm{s}$ binary phase-shift keyed (BPSK) transmitter with a $2 \mathrm{~W}$ linear power amplifier in a T-39 Saberliner aircraft. The baseband NRZ PCM PN waveform was filtered by a 7th order elliptic low-pass filter with a $3 \mathrm{~dB}$ frequency of $10 \mathrm{MHz}$ to limit the spectrum of the resulting RF modulated signal. The transmit antenna was a vertically polarized, hemispherically omni-directional antenna mounted under the aircraft fuselage. GPS data were recorded on board the aircraft for data correlation during postflight processing.

The receiving station used a parabolic reflector which tracked the airborne transmitter. This antenna was located at the main telemetry receiving complex (Building 5790) at Edwards AFB. The received signal was downconverted to a linear $70 \mathrm{MHz} \mathrm{IF}$, filtered by an IF bandpass filter, and sampled at $100 \mathrm{Msamples/s}$ using a high-speed sampling oscilloscope. In addition, the receiver AGC voltage was sampled at $50 \mathrm{ksamples} / \mathrm{s}$ and tagged with GPS-derived time stamps for calibration purposes during the postflight processing.

Two flight paths were used for the channel sounding measurements as illustrated in Fig. 2. The first is Cords Road, which is an approximately east-west flight corridor just north of the main telemetry receiving complex at Edwards AFB. The west end of the Cords Road run is located at $35^{\circ}$

\footnotetext{
${ }^{1} \mathrm{~A}$ PN sequence was chosen since it can be used to identify multipath reflections in the received signal using well-known cross correlation methods [8]. The cross correlation method identifies a multipath reflection only when its delay (relative to other propagation paths) is greater than twice the chip time. In this system, the minimum resolvable delay is $200 \mathrm{~ns}$ which is much greater than the delays produced by the system geometry. While there are multipath reflections that arrive with delays greater than the 200 ns resolution, the amplitudes are very small and are hard to extract from the cross correlation data. Some PN cross correlation results for the Edwards AFB data are presented in [9].
}
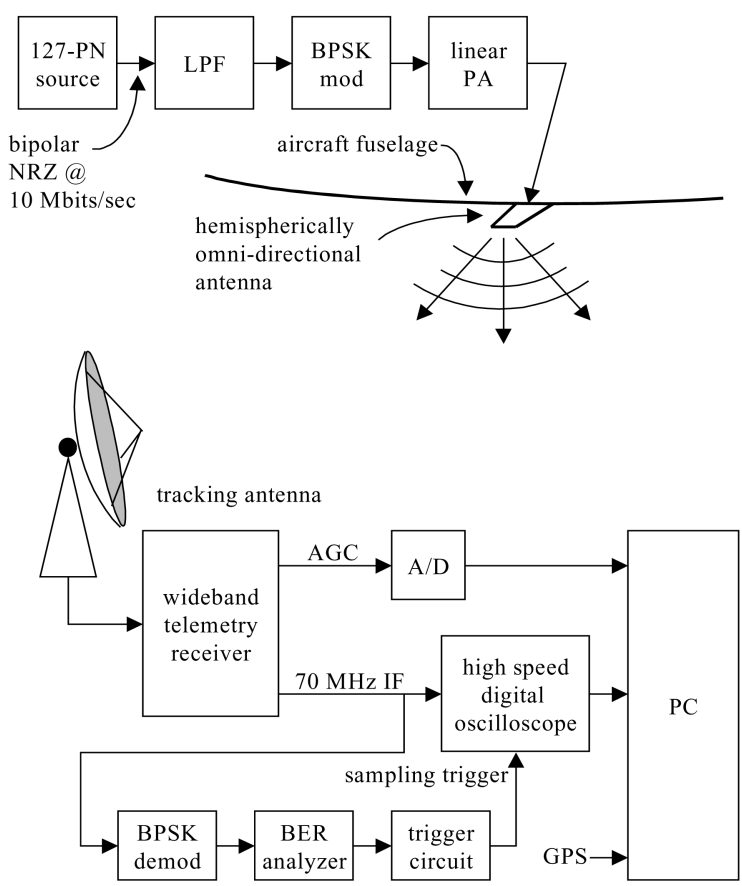

Fig. 1. Block diagram of experimental configuration used for channel sounding experiments.

$5.22^{\prime} \mathrm{N}, 117^{\circ} 59.98^{\prime} \mathrm{W}$ and the east end is located at $35^{\circ} 4.95^{\prime} \mathrm{N}, 117^{\circ} 3.89^{\prime} \mathrm{W}$. The channel sounding flights conducted along the Cords Road corridor were at an altitude of 5,000 ft AMSL. The second is Black Mountain which is also an east-west flight corridor and is north of the Cords Road flight path. The west end of the Black Mountain run is located at $35^{\circ}$ $12.26^{\prime} \mathrm{N}, 117^{\circ} 52.17^{\prime} \mathrm{W}$ and the east end is located at $35^{\circ} 11.46^{\prime} \mathrm{N}, 116^{\circ} 53.90^{\prime} \mathrm{W}$. The channel sounding flights conducted along the Black Mountain corridor were at altitudes of 5,000 and 10,000 ft AMSL. The main telemetry receiving complex is at $34^{\circ} 53.62^{\prime} \mathrm{N}$, $118^{\circ} 0.68^{\prime} \mathrm{W}$ at an altitude of $2966 \mathrm{ft}$ AMSL. The dry-lake bed that forms the reflecting surface is at an altitude of $2300 \mathrm{ft}$ AMSL.

Two modes of operation were used to produce the data analyzed here. In the first mode, sampling was triggered by error events generated by the BPSK demodulator. During each trigger event, the digital oscilloscope recorded 10 consecutive data segments spaced $T_{\Delta \text { seg }} \mathrm{s}$ apart with duration $T_{\text {seg }}=100 \mu \mathrm{s}$ (or 10,000 samples). In the second mode, sampling is performed continuously but interrupted by data transfer to a file when the sampling oscilloscope memory is full. The sampling process is performed in short bursts spaced $T_{\Delta \mathrm{seg}}=20 \mathrm{~ms}$ apart with duration $T_{\text {seg }}=50 \mu \mathrm{s}(5,000$ samples $)$. With these numbers, oscilloscope memory allowed the sampling of 800 segments between data transfer events. In this way, snapshots of the channel impulse response were produced every $T_{\Delta \text { seg }}$ s. These details are summarized in Table I. 


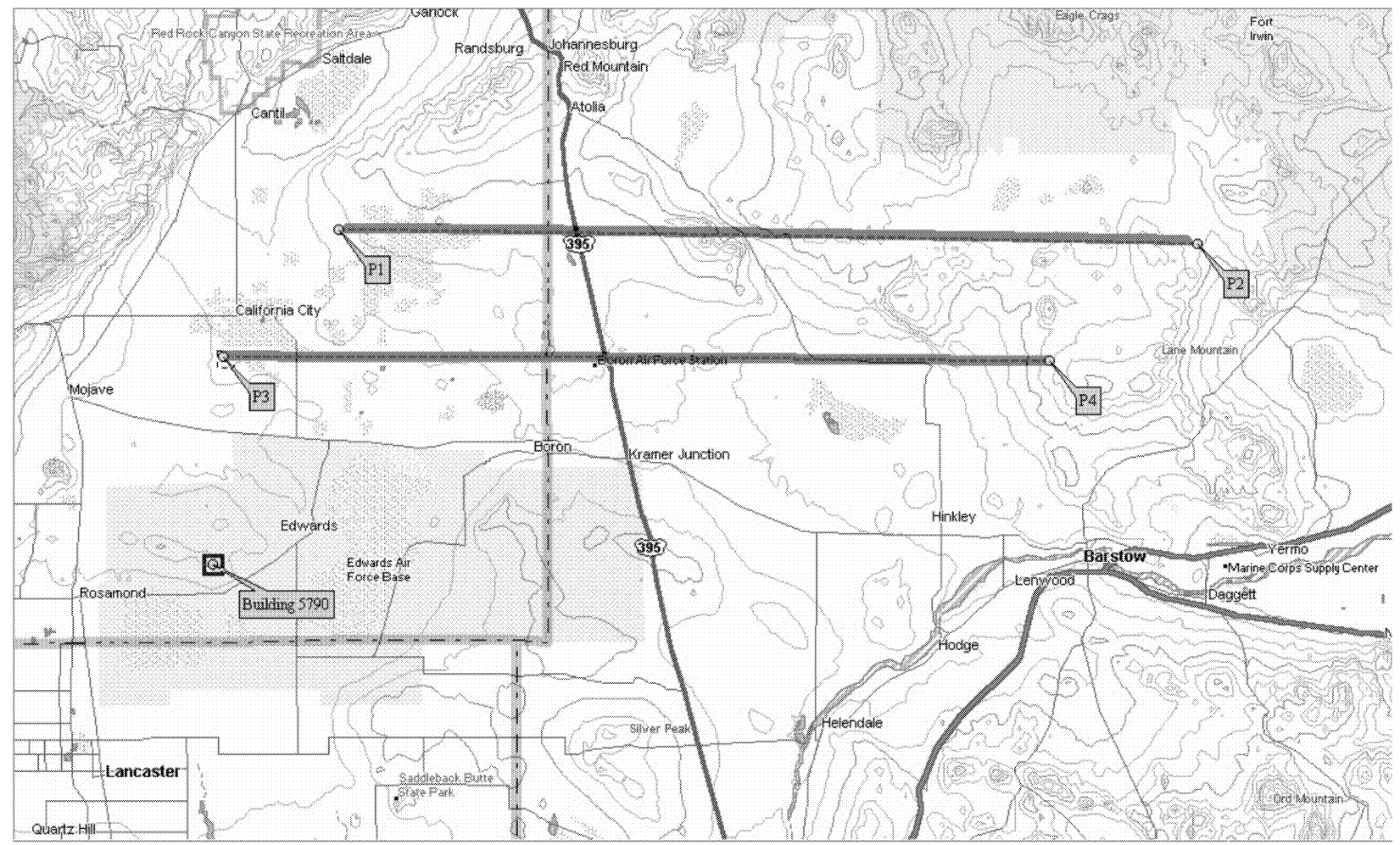

Fig. 2. Black Mountain (between points P1 and P2) and Cords Road (between points P3 and P4) flight paths at Edwards AFB. Receiver for all channel sounding runs was located at Building 5790.

TABLE I

Experimental Configuration Summary

\begin{tabular}{cccccccc}
\hline \hline $\begin{array}{c}\text { Flight } \\
\text { Number }\end{array}$ & Mode & $T_{\Delta \text { seg }}(\mathrm{ms})$ & $T_{\text {seg }}(\mu \mathrm{s})$ & $\begin{array}{c}\text { Carrier } \\
\text { Frequency (MHz) }\end{array}$ & $\begin{array}{c}\text { Antenna } \\
\text { Diameter } \\
\text { at Receiver (ft) }\end{array}$ & Location & Date \\
\hline 10 & triggered & 200 & 100 & 1510.5 & 8 & EAFB & 10 Dec 98 \\
11 & triggered & 150 & 100 & 2344.5 & 15 & EAFB & 16 Feb 99 \\
12 & triggered & 250 & 100 & 2360.5 & 8 & EAFB & 22 Feb 99 \\
18 & continuous & 20 & 50 & 1460.5 & 4,8 & EAFB & 28 Jul 99 \\
\hline
\end{tabular}

\section{B. Data Processing}

The data processing used samples of the transmitted signal $x\left(n T_{s}\right) 70 \mathrm{MHz} \mathrm{IF}$ and samples of the received signal $y\left(n T_{s}\right)$ at $70 \mathrm{MHz} \mathrm{IF}$, where $T_{s}=10 \mathrm{~ns}$ is the sampling time. The Bartlett method (periodogram averaging) [10] was then used to estimate the power spectral densities $S_{x x}\left(e^{j \Omega_{m}}\right)$ and $S_{y y}\left(e^{j \Omega_{m}}\right)$ of $x\left(n T_{s}\right)$ and $y\left(n T_{s}\right)$, respectively, using the $M=1270$-point discrete Fourier transform (DFT). ${ }^{2}$ The DFT frequency bins are $\Omega_{m}=2 \pi m / M$ for $m=$ $0,1, \ldots, M-1$. From these estimates, an estimate of the magnitude squared of the channel transfer function

\footnotetext{
${ }^{2}$ Since the length-127 PN sequence is repeated every 127 bits, the transmitted signal is periodic and the true power spectral density of $x(t)$ is discrete [11]. The length of the DFT was chosen to match a single period of $x\left(n T_{s}\right)$ so that the DFT bin centers are aligned with the spectral lines of the power spectral density.
}

is obtained

$$
\left|\hat{H}\left(e^{j \Omega_{m}}\right)\right|^{2}=\frac{S_{y y}\left(e^{j \Omega_{m}}\right)}{S_{x x}\left(e^{j \Omega_{m}}\right)} .
$$

Thus $\left|\hat{H}\left(e^{j \Omega_{m}}\right)\right|^{2}$ is a sampled version of $\left|\hat{H}\left(e^{j \Omega}\right)\right|^{2}$, the DTFT of the channel impulse response. Due to the bandlimited nature of the channel input and corresponding output, $\left|\hat{H}\left(e^{j \Omega}\right)\right|^{2}$ is also bandlimited and has support in the frequency domain for $W_{1} \leq \Omega \leq$ $W_{2}$. Let $W=\left[W_{1}, W_{2}\right]$ be this region of support and let

$$
\mathcal{M}=\left\{m \mid W_{1} \leq \Omega_{m} \leq W_{2}\right\}
$$

be the set of indices corresponding to the frequency bins in the region of support.

The estimate $\left|\hat{H}\left(e^{j \Omega_{m}}\right)\right|^{2}$ is compared with the transfer function of the model to estimate the model parameters (i.e., the amplitudes and delays of the multipath reflections). We begin by computing the 
Fourier transform of the model (3) to obtain

$$
H(\omega)=1+\sum_{k=1}^{L-1} \Gamma_{k} \exp \left\{-j\left(\omega \tau_{k}+\omega_{c} \tau_{k}\right)\right\} .
$$

The continuous-time channel transfer function (6) is bandlimited by setting $H(\omega)=0$ for $\omega T_{s} \notin W$. Using the relationship between bandlimited continuous-time systems and the equivalent discrete-time systems [12, ch. 7], the equivalent discrete-time channel transfer function is given by

$$
\begin{aligned}
& H\left(e^{j \Omega}\right)= \\
& \begin{cases}1+\sum_{k=1}^{L-1} \Gamma_{k} \exp \left\{-j\left(\Omega \frac{\tau_{k}}{T_{s}}+\omega_{c} \tau_{k}\right)\right\} & \Omega \in W \\
0 & \text { else }\end{cases}
\end{aligned}
$$

Equation (7) is a function of 2(L-1) parameters which we define as the set

$$
\mathcal{S}=\left\{\Gamma_{1}, \tau_{1}, \Gamma_{2}, \tau_{2}, \ldots, \Gamma_{L-1}, \tau_{L-1}\right\} .
$$

The optimal parameter set $\mathcal{S}_{\text {opt }}$ is determined using a modified least squares criterion:

$$
\begin{aligned}
& \mathcal{S}_{\text {opt }}= \\
& \underset{\mathcal{S}}{\operatorname{argmin}}\left\{\sum_{m \in \mathcal{M}}\left|10 \log _{10}\left(\left|H\left(e^{j \Omega_{m}} ; \mathcal{S}\right)\right|^{2}\right)-10 \log _{10}\left(\left|\hat{H}\left(e^{j \Omega_{m}}\right)\right|^{2}\right)\right|^{2}\right\}
\end{aligned}
$$

where the notation $H\left(e^{j \Omega_{m}} ; \mathcal{S}\right)$ has been used in place of $H\left(e^{j \Omega_{m}}\right)$ to emphasize the fact that the model is a function of the parameters in the set $\mathcal{S}$. The decibel criterion was chosen to force the least-squares minimization algorithm to weight modeling errors corresponding to frequencies in multipath nulls equally with modeling errors corresponding to frequencies with unfaded signals. This was needed to emphasize the structure of the multipath nulls which depend on the delays thereby improving the estimates of the delays. Note that if the usual least-squares criterion were used, modeling errors in the nulls, where the amplitude is small, would not make a sufficient contribution to the total least squares error to produce accurate modeling results.

\section{MODELING RESULTS}

\section{A. Number of Multipath Reflections}

The number of multipath reflections $L$ used in the model represents a trade-off between model accuracy and complexity. In general, the higher $L$ is, the more accurate the channel model is, but the less useful it is since information about each multipath reflection is required. With this in mind, the first goal of our modeling process was to determine the minimum number of paths required to represent the multipath interference with reasonable accuracy. A thorough examination of the data showed that $L=3$ is a good value. The most extreme case is shown in Fig. 3 which plots the modeling results for a segment of data from Flight 10 along the Black Mountain flight path. The power spectra of the transmitted and received signals are illustrated in Fig. 3(a) and (b), respectively. The estimate of the channel transfer function $\left|\hat{H}\left(e^{j \Omega}\right)\right|^{2}$ is shown by the solid line in Fig. 3(c) and (d). The dashed line in Fig. 3(c) is the best fit for the $L=2$ channel model. We observe that the two-ray model does not possess enough degrees of freedom to represent the structure of the multipath distortion. Increasing $L$ to 3 and following the modeling procedure produces the model shown by the dashed line in Fig. 3(d). The 3-ray model is needed to capture the "ripple" effect observed in the channel transfer function estimate.

All of the data runs measured at Edwards AFB are well modeled by a three-ray model. The channel consists of a line-of-sight propagation path and two multipath reflections. The first reflection has a large relative amplitude and short delay and is caused by a specular ground "bounce" or reflection. This conclusion is supported by using the location information recorded during the the test flight to compute the system geometry. The second reflection is a much weaker reflection whose delay is an order magnitude larger. Given the differential path delays observed, we conclude that this reflection is caused by foothills and low mountains situated in between the airborne transmitter and the ground-based receiver. Since the terrain variations in this region appear random as the airborne transmitter progresses along its flight trajectory, the characteristics of this multipath reflection are better modeled as random variables.

\section{B. Properties of First Multipath Reflection}

The first ray is well modeling as a single "ground bounce" off a flat, smooth earth. The typical flight geometry, illustrated in Fig. 4 reveals why this is so. The flat reflecting surface between the airborne transmitter and ground-based receiver represents the dry lake beds typical of test ranges located in the deserts of the western United States. For a receive antenna with beamwidth $\theta_{a}$ set at elevation angle $\theta_{e}$, a specular reflection with grazing angle $\theta_{g}$ will only cause multipath interference when the specular reflection arrives within the mainlobe of receive antenna gain pattern; that is when

$$
\theta_{e}+\theta_{g}<\frac{\theta_{a}}{2}
$$

For aeronautical telemetry applications, antenna beamwidths range from approximately $6^{\circ}$ for the $8 \mathrm{ft} \mathrm{L}$-band antenna to about $3^{\circ}$ for the $15 \mathrm{ft} \mathrm{L}$-band antenna at Edwards AFB. Given this scenario, 


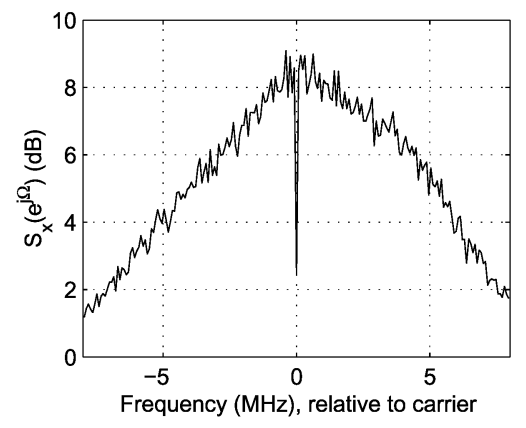

(a)

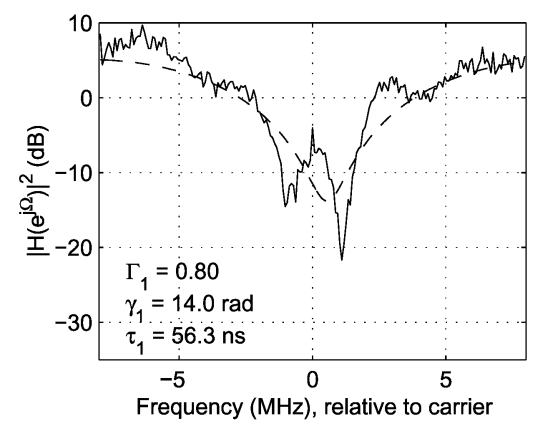

(c)

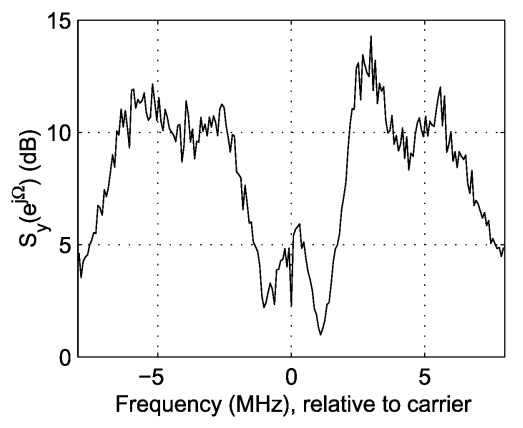

(b)

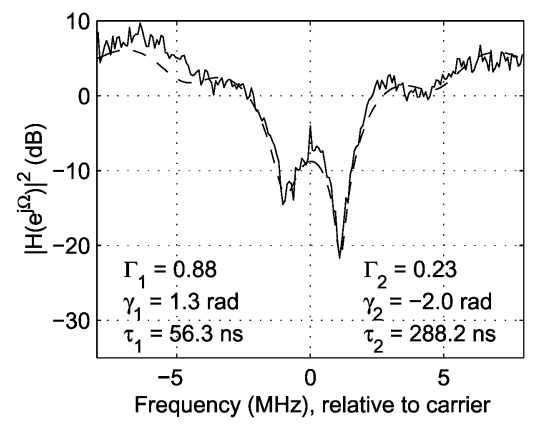

(d)

Fig. 3. Data processing example from Flight 10. (a) Power spectral density of transmitted signal. (b) Power spectral density of received signal. (c) Estimate of channel transfer function (solid line) and best 2-ray model fit (dashed line). (d) Estimate of channel transfer function (solid line) and best 3-ray model fit (dashed line).

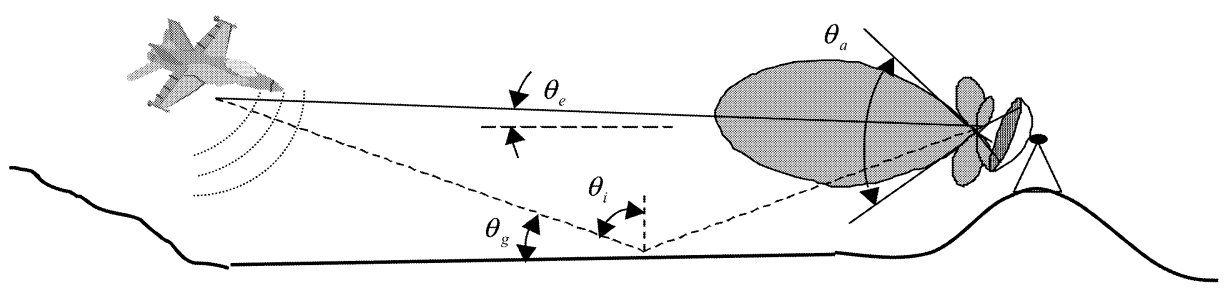

Fig. 4. Geometry of aeronautical telemetry channel.

multipath interference is most likely to occur when the elevation angle $\theta_{e}$ is small and the environmental geometry supports a multipath reflection with a very small grazing angle.

The physical properties of the specular reflection are well understood in electromagnetic theory [13]. Given the propagation geometry illustrated in Fig. 4, the reflection coefficient is well modeled as E-field reflection at an interface between free space and a semi-infinite dielectric. For vertical and horizontal polarizations, the reflection coefficients are

$$
\begin{gathered}
\Gamma_{V}=\frac{-\cos \theta_{i}+\sqrt{\frac{\epsilon_{0}}{\epsilon_{1}}} \sqrt{1-\frac{\epsilon_{0}}{\epsilon_{1}} \sin ^{2} \theta_{i}}}{\cos \theta_{i}+\sqrt{\frac{\epsilon_{0}}{\epsilon_{1}}} \sqrt{1-\frac{\epsilon_{0}}{\epsilon_{1}} \sin ^{2} \theta_{i}}} \\
\Gamma_{H}=\frac{\cos \theta_{i}-\sqrt{\frac{\epsilon_{1}}{\epsilon_{0}}} \sqrt{1-\frac{\epsilon_{0}}{\epsilon_{1}} \sin ^{2} \theta_{i}}}{\cos \theta_{i}+\sqrt{\frac{\epsilon_{1}}{\epsilon_{0}}} \sqrt{1-\frac{\epsilon_{0}}{\epsilon_{1}} \sin ^{2} \theta_{i}}},
\end{gathered}
$$

respectively, where $\epsilon_{0}=8.85 \times 10^{-12} \mathrm{~F} / \mathrm{m}$ is the permittivity of free space and $\epsilon_{1}$ is the permittivity of the reflecting media. For dry earth, $\epsilon_{1}=3 \epsilon_{0}+3 \times$ $10^{-4} / j \omega_{c}$ [13]. As the grazing angle $\theta_{g}$ gets small, the incidence angle $\theta_{i}$ approaches $90^{\circ}$ so that $\Gamma_{V} \rightarrow+1$ and $\Gamma_{H} \rightarrow-1$. Expressions for the delay $\tau_{1}$ and grazing angle $\theta_{g}$ assuming a flat smooth earth are given by (19) and (20), respectively, in the Appendix.

As an example, the magnitude, phase, and delay of the first multipath reflection predicted by this assumption is plotted in Fig. 5 for a $16 \mathrm{~s}$ segment of data from the Cords Road run. Also included in the plot are the modeling results. We observe close agreement between the predicted values and modeling values for $\tau_{1}$ and $\left|\Gamma_{1}\right|$. The gap in the modeling results (from about 9 to $14 \mathrm{~s}$ ) is due to the inability of the analysis procedure to model the multipath when the spectral null is phased so that it does not occur within the band occupied by the transmitted signal. Variations in the modeling for $\left|\Gamma_{1}\right|$ result from the fact that the Earth is not exactly smooth. This roughness causes 

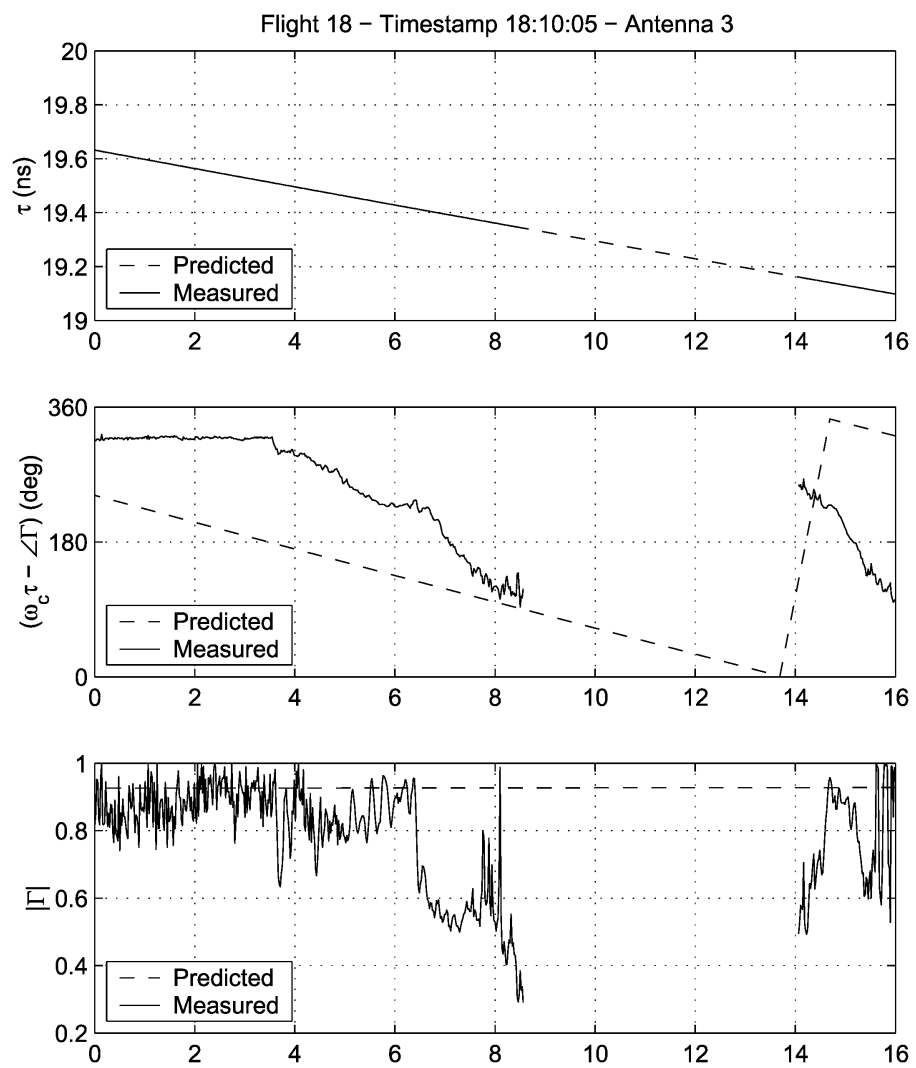

Fig. 5. Comparison of predicted multipath parameters (dotted lines) with measured values (solid lines) at timestamp 18:10:05 during Flight 18 at Edwards AFB. Top: delay. Middle: phase. Bottom: magnitude.

some diffuse scattering that reduces the power in the reflection as seen by the receive antenna.

For an airborne transmitter following the Cords Road flight path at an altitude of 5,000 ft, the simple geometric model predicts $\left|\Gamma_{1}\right|$ ranges from 0.81 to 0.95 (west to east) and $\tau_{1}$ ranges from 55 to $13 \mathrm{~ns}$ (west to east). Likewise for the Black Mountain flight path at $5,000 \mathrm{ft},\left|\Gamma_{1}\right|$ ranges from 0.89 to 0.96 (west to east) and $\tau_{1}$ ranges from 31 to $11 \mathrm{~ns}$ (west to east). At $10,000 \mathrm{ft}\left|\Gamma_{1}\right|$ ranges from 0.74 to 0.90 (west to east) and $\tau_{1}$ ranges from 87 to $32 \mathrm{~ns}$ (west to east). Model parameters obtained from the data processing at various points along these flight paths for $\Gamma_{1}$ and $\tau_{1}$ agreed very well with these values.

The dynamic behavior of the first reflection is due to changes in the reflection geometry as the airborne transmitter proceeds along its flight trajectory. The location of the spectral null is determined by the overall phase of the multipath reflection which is

$$
\theta_{\text {total }}=\angle \Gamma_{1}-\omega_{c} \tau_{1} .
$$

As the airborne transmitter moves through space, $\angle \Gamma_{1}$ and $\tau_{1}$ change. The rate of change of these values is determined by the time derivatives of the differential delay $\tau_{1}$ and grazing angle $\theta_{g}$. Expressions for these values are given by (21) and (22) in the Appendix where it is observed that $\dot{\theta}_{g}$ is negligibly small for the geometries of interest (i.e. $\theta_{g}$ is well approximated by a constant). For the geometries of interest, $\dot{\tau}$ is also small. But since $\omega_{c}$ is large, the product is large enough to observe. As a result, $\theta_{\text {total }}$ is proportional to $\dot{\tau}$ and the null appears to "sweep" through the spectral band occupied by the modulated signal. This phenomenon is illustrated in Fig. 6. Note that the null progresses through the signal bandwidth as small changes in the differential delay impose significant changes in $\theta_{\text {total }}$. A plot of $\dot{\tau}_{1}$ calculated using (21) for the three channel sounding flight paths is shown in Fig. 7. The product $\omega_{c} \dot{\tau}_{1}$ has units rads/s and indicates the rate at which the null sweeps across the spectrum. ${ }^{3}$

\section{Properties of Second Multipath Reflection}

The second reflection is a result of bounces off the foothills and mountains along the flight path for both Cords Road and Black Mountain. Since these terrain features are much more uneven and unpredictable, the resulting multipath properties appear random in nature. As a consequence, a statistical characterization is adopted.

A histogram of the complex amplitude $\Gamma_{2}$ for both the Cords Road and Black Mountain runs are

\footnotetext{
${ }^{3}$ Since the nulls occur every $1 / \tau_{1} \mathrm{~Hz}$, the time required for $\omega_{c} \dot{\tau}_{1}$ to change by $2 \pi$ is the time required for the null to sweep through $1 / \tau_{1} \mathrm{~Hz}$ on a spectrum analyzer.
} 


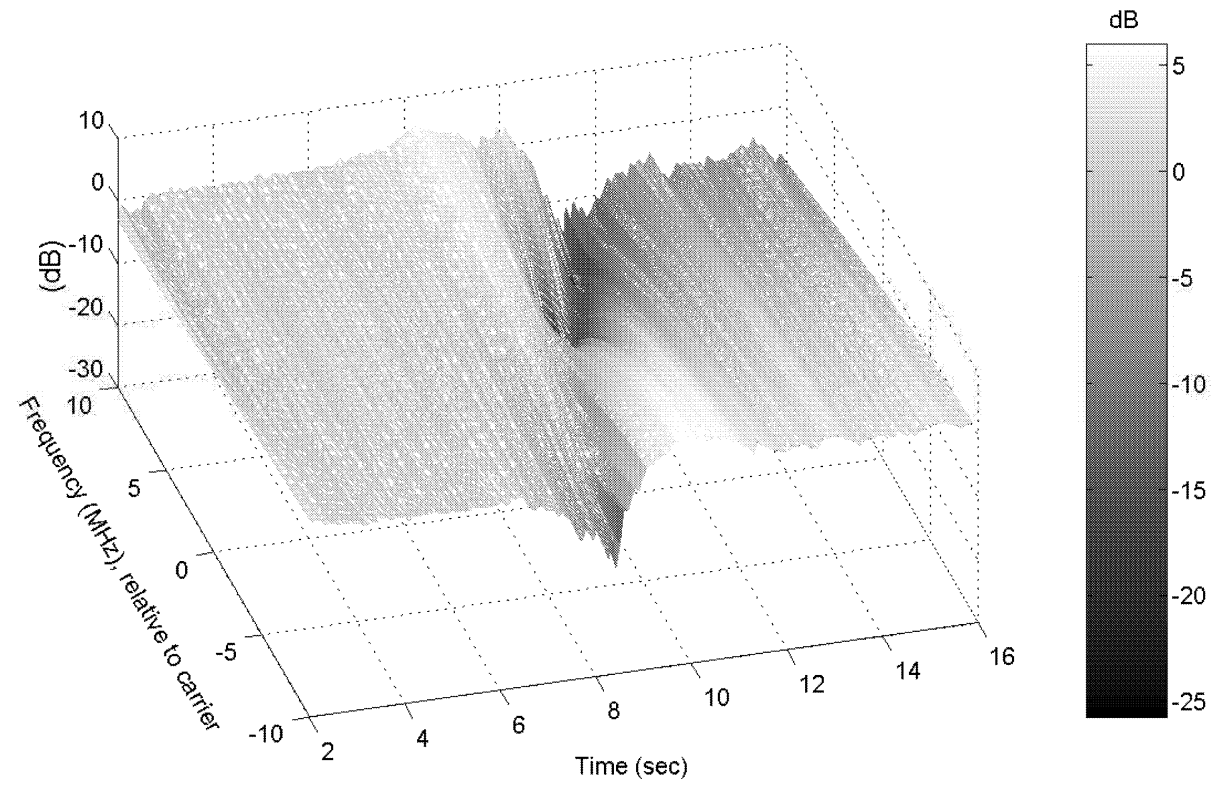

Fig. 6. Sequence of channel transfer functions for Flight 18. Each slice in plot is a plot of channel transfer function based on best fit model parameters.

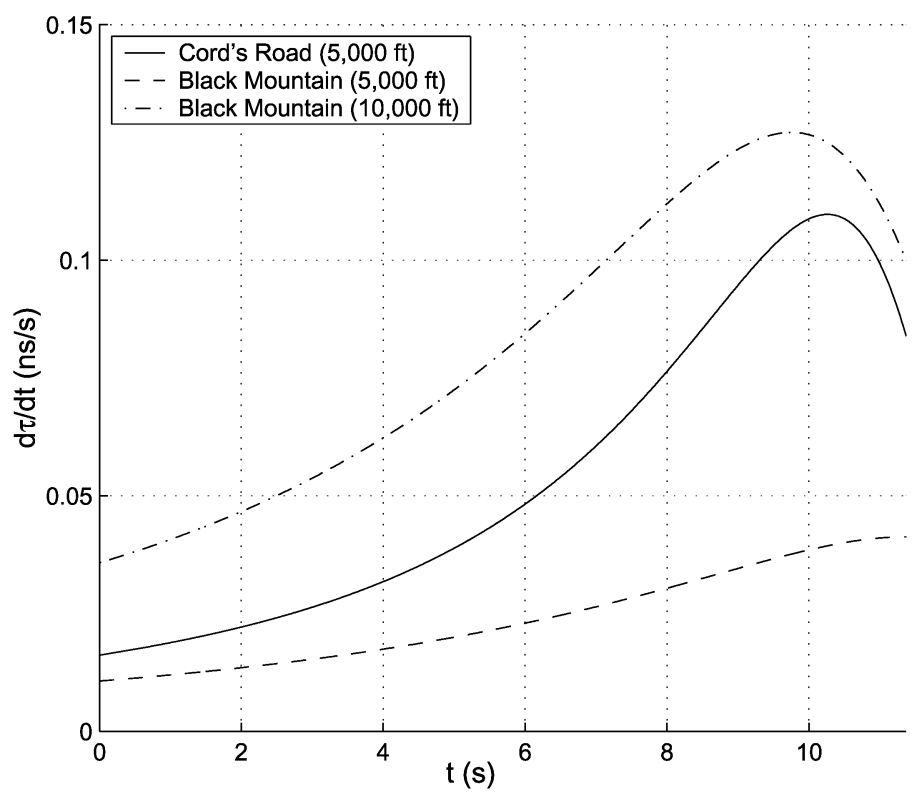

Fig. 7. Plot of $\dot{\tau}_{1}$ for three channel sounding flight paths.

shown in Figs. 8 and 9, respectively. In each figure, the solid line is a plot of the Gaussian probability density function (pdf) defined by the sample mean and variance. The amplitudes are well approximated by a complex valued Gaussian random variable where the real and imaginary components each have zero-mean and variance $1.6 \times 10^{-3}$. Consequently, $\left|\Gamma_{2}\right|$ is Rayleigh distributed and $\angle \Gamma_{2}$ is uniformly distributed.

The delay $\tau_{2}$ is statistically characterized using the power delay profile [6]. The power delay profiles for Cords Road, Black Mountain, and the two combined are shown in Figs. 10, 11, and 12, respectively. The mean excess delay $\tau_{e}$ and the delay spread $\sigma_{\tau}$ are summarized as follows.

\begin{tabular}{cccc}
\hline & $\begin{array}{c}\text { Flight 18 } \\
\text { Cords Road } \\
(5,000 \mathrm{ft})\end{array}$ & $\begin{array}{c}\text { Flight 18 } \\
\text { Black Mountain } \\
(5,000 \mathrm{ft})\end{array}$ & $\begin{array}{c}\text { Flight 18 } \\
\text { All Data } \\
(5,000 \mathrm{ft})\end{array}$ \\
\hline$\tau_{e}$ & $155 \mathrm{~ns}$ & $154 \mathrm{~ns}$ & $155 \mathrm{~ns}$ \\
$\sigma_{\tau}$ & $77 \mathrm{~ns}$ & $61 \mathrm{~ns}$ & $74 \mathrm{~ns}$ \\
\hline
\end{tabular}

The dynamic behavior of the second reflection is characterized using the autocorrelation function 

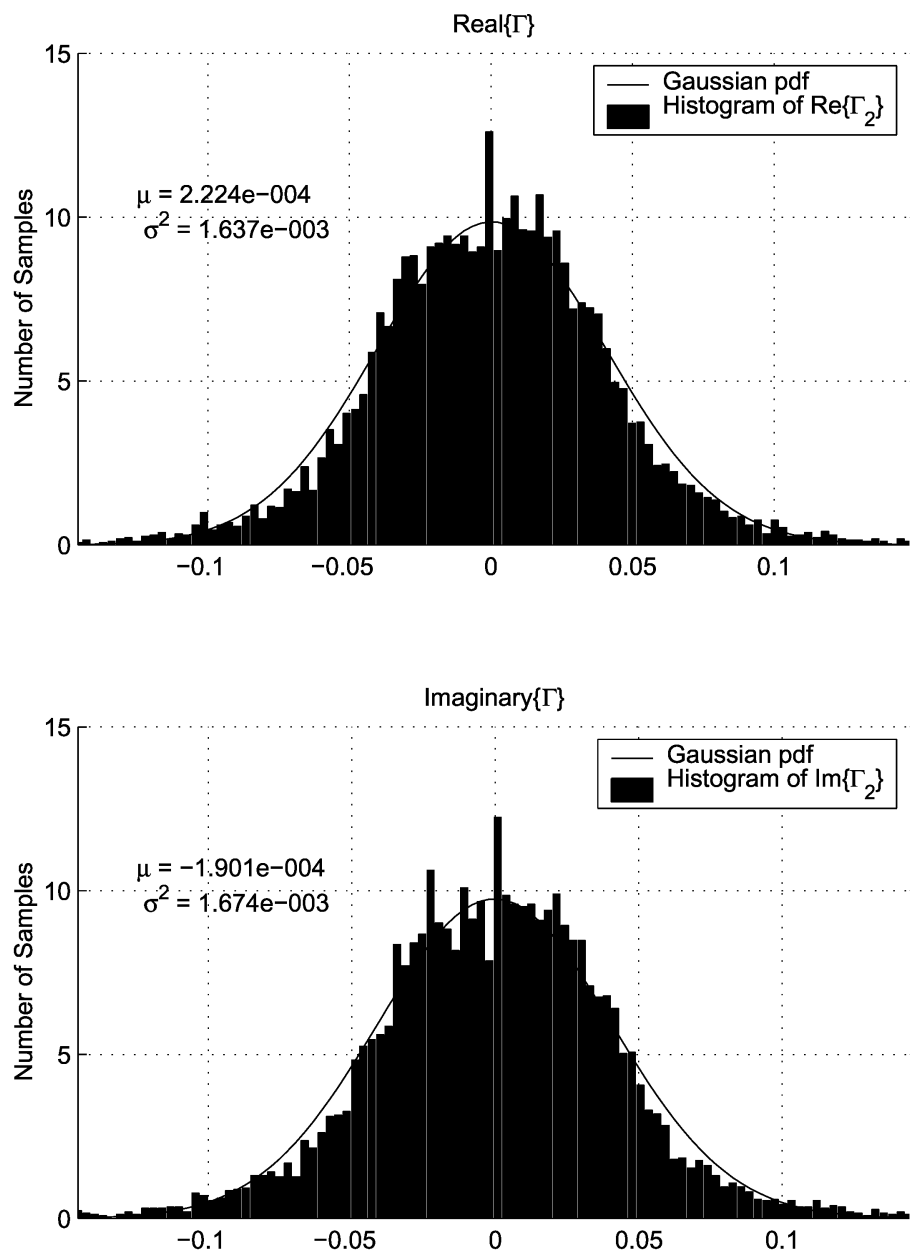

Fig. 8. Cords Road data set from Flight 18 at Edwards AFB. Histograms of real (top graph) and imaginary (bottom graph) parts of $\Gamma_{2}$ compared with Gaussian pdf formed from mean and variance of each data set.

$$
\begin{aligned}
R_{\Gamma_{2}}(\Delta t) & =E\left\{\Gamma_{2}(t) \Gamma_{2}^{*}(t-\Delta t)\right\} \\
& \approx \frac{1}{N} \sum_{n=0}^{N-1} \Gamma_{2}(n) \Gamma_{2}^{*}(n-\Delta t)
\end{aligned}
$$

where the notation $\Gamma_{2}(n)$ means the model parameter $\Gamma_{2}$ obtained from the data corresponding to the $n$th segment. A plot of this function for a $16 \mathrm{~s}$ interval from the Cords Road run at $5000 \mathrm{ft}$ is shown in Fig. 13. This plot, typical of all data runs at Edwards AFB, shows that the sequence of $\Gamma_{2}$ is uncorrelated. As such, $\Gamma_{2}$ changes rapidly with position (and time).

\section{CONCLUSIONS}

Channel sounding data collected at Edwards AFB, CA was used to characterize the multipath propagation observed on the aeronautical telemetry channel. A channel model based on an analysis of this data was developed and presented. The channel model consists of three propagation paths: a line-of-sight propagation path and two specular reflections. The first specular reflection is well modeled as a single ground bounce from a flat, smooth earth. The amplitude and delay are determined from the flight profile. For the flight paths used for channel sounding experiments, the amplitude of this path ranged from $70 \%$ to $96 \%$ of the line-of-sight path and the delay was $10-80$ ns relative to the line-of-sight path. The dynamic behavior of this reflection was also analyzed. It was shown that small changes in the position of the airborne transmitter cause the spectral null associated with this multipath reflection to sweep through the spectral band occupied by the modulated signal.

The second reflection is a much lower amplitude propagation path that is caused by irregular terrain (foothills and mountains) along the propagation path. Since the irregular terrain varies in an unpredictable way, the amplitudes and delays appear to vary in a random way. The amplitude is well modeled by complex valued, zero-mean Gaussian random variable. The resulting amplitude is on the order $2 \%$ to $8 \%$ of the line-of-sight amplitude. The sequence of complex amplitudes is uncorrelated which indicates rapid variations in time and space. The mean excess delay is $155 \mathrm{~ns}$ with an rms delay spread of 74 ns. 

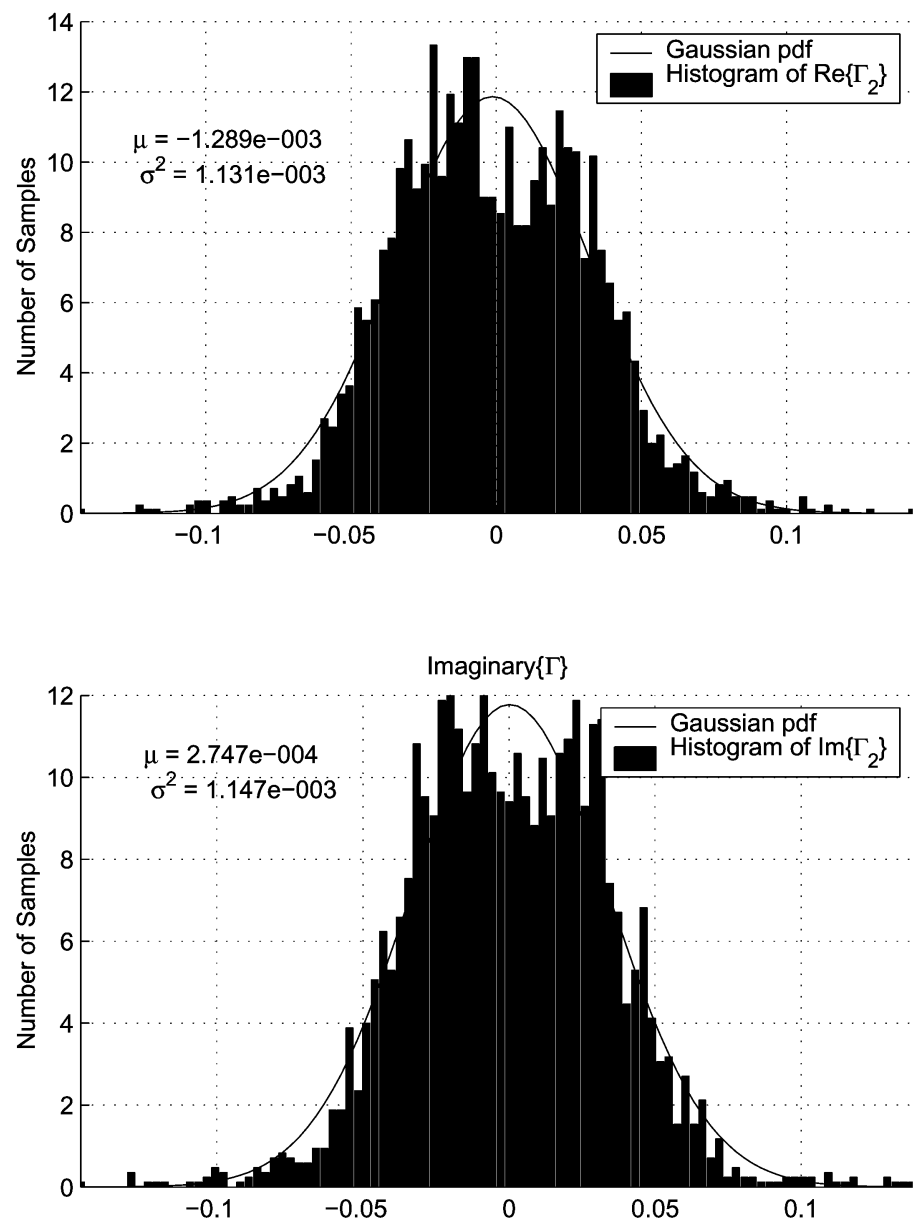

Fig. 9. Black Mountain data set from Flight 18 at Edwards AFB. Histograms of real (top graph) and imaginary (bottom graph) parts of $\Gamma_{2}$ compared with Gaussian pdf formed from mean and variance of each data set.

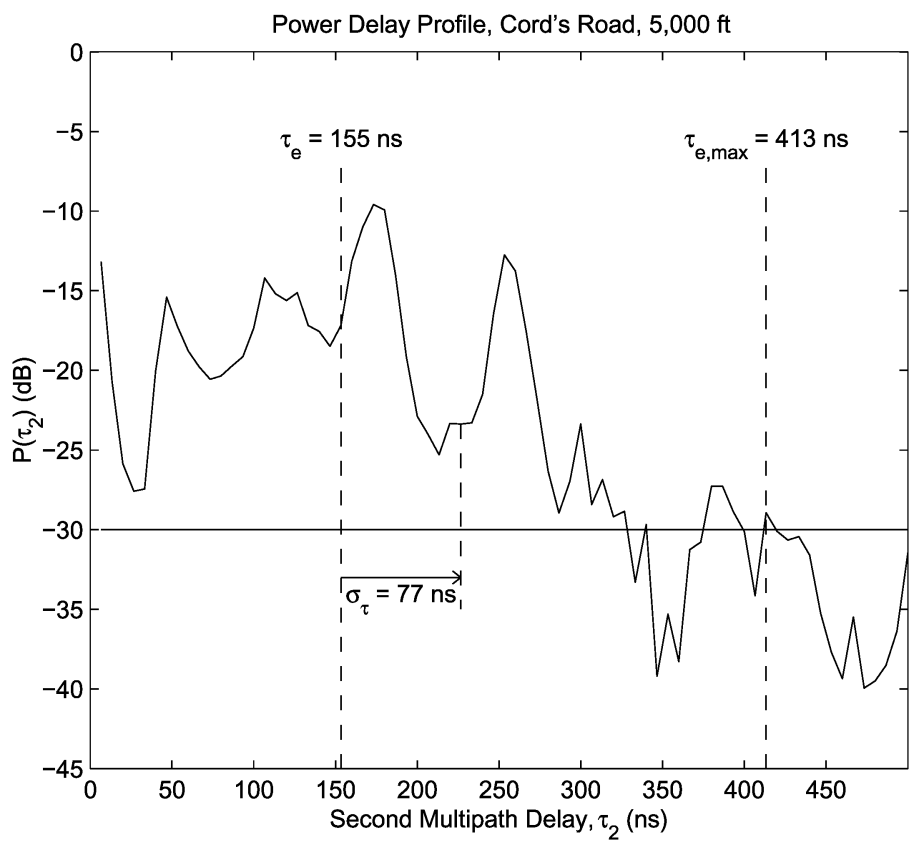

Fig. 10. Power delay profile for second multipath reflection. Data shown here was collected at Edwards AFB along Cords Road flight path during Flight 18. 


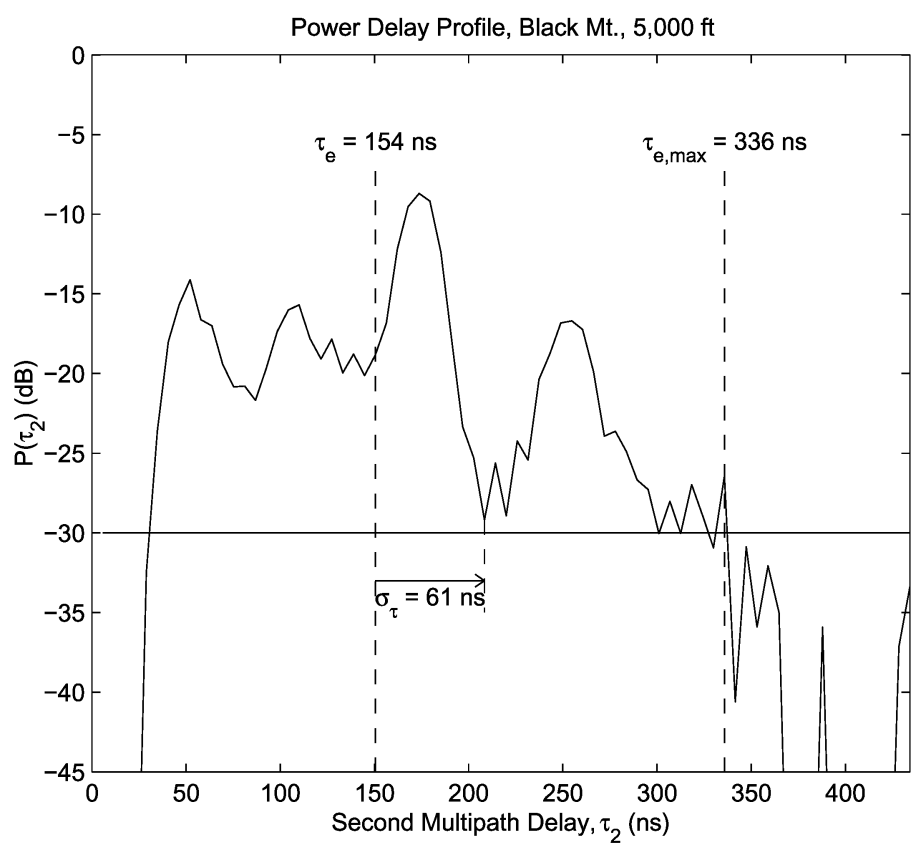

Fig. 11. Power delay profile for second multipath reflection. Data shown here was collected at Edwards AFB along Black Mountain flight path during Flight 18.

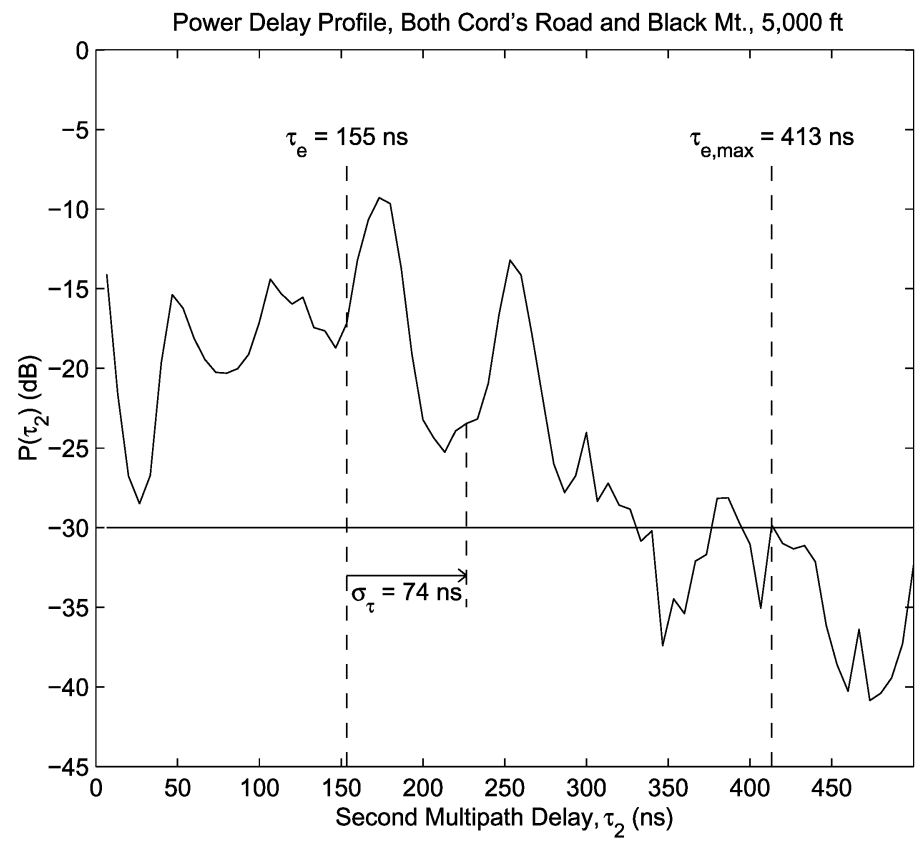

Fig. 12. Power delay profile for second multipath reflection for combined data from Figs. 10 and 11.

The dominant feature of the multipath interference is the spectral null generated by the first multipath reflection. The time variations of this reflection depend on the flight path of the airborne transmitter and are slow enough to be tracked by an adaptive equalizer. The second multipath causes a small amplitude "ripple" in the channel transfer function that varies quickly with time. The changes in this ripple are probably too rapid to be tracked by an adaptive equalizer. Fortunately, this characteristic is not the dominant multipath distortion on this channel.

\section{APPENDIX A. GEOMETRIC APPROXIMATIONS USED FOR FLAT EARTH MODEL}

The geometry of the flight path assuming a flat-smooth earth is illustrated in Fig. 14. In Fig. 14(a), the transmitter location $\mathbf{T}^{\prime}=\left[x_{T}^{\prime}, y_{T}^{\prime}, z_{T}^{\prime}\right]^{\mathrm{T}}$, the receiver location $\mathbf{R}^{\prime}=\left[x_{R}^{\prime}, y_{R}^{\prime}, z_{R}^{\prime}\right]^{\mathrm{T}}$, and the specular point $\mathbf{S}^{\prime}=\left[x_{S}^{\prime}, y_{S}^{\prime}, z_{S}^{\prime}\right]^{\mathrm{T}}$ are plotted on a south-east-up coordinate system [14] $\left(x^{\prime}, y^{\prime}, z^{\prime}\right)$ centered at sea level at the latitude and longitude of the receiver. For our simple model of a flat, level reflecting surface, the 

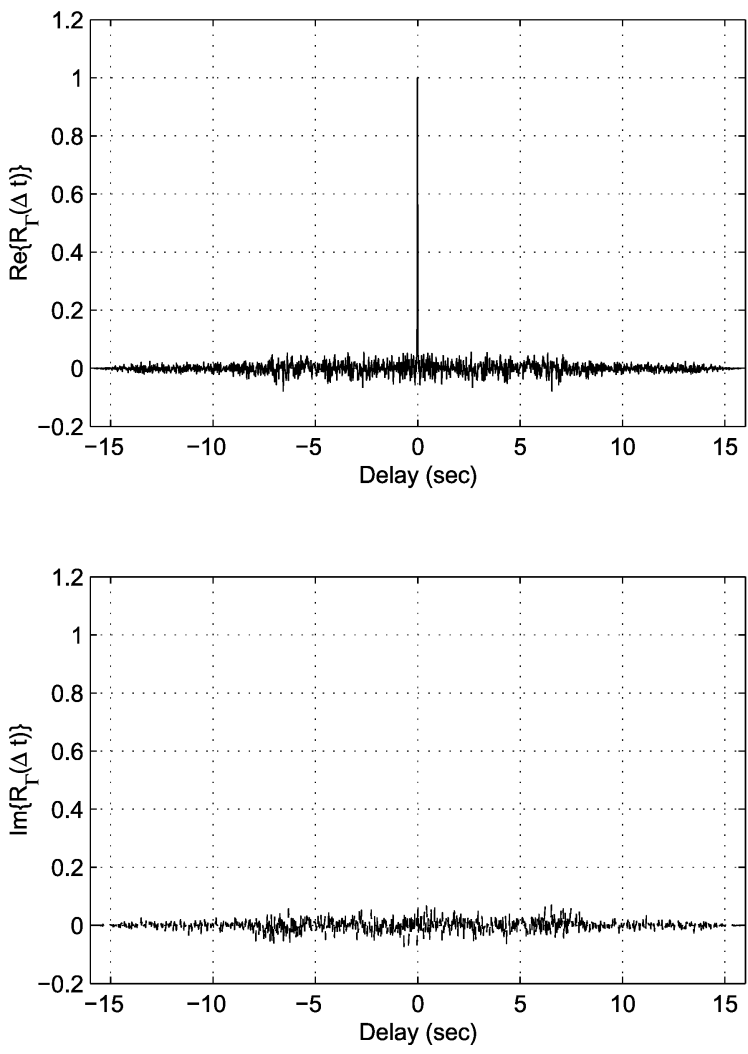

Fig. 13. Autocorrelation function for $\Gamma_{2}$ for $16 \mathrm{~s}$ interval from the Cords Road run at $5000 \mathrm{ft}$.

points $\mathbf{T}^{\prime}, \mathbf{R}^{\prime}$, and $\mathbf{S}^{\prime}$ reside in a plane as shown. As such, the three points may by plotted in a new coordinate system $(x, y, z)$ which is produced from $\left(x^{\prime}, y^{\prime}, z^{\prime}\right)$ by a clockwise rotation about the $z^{\prime}$ axis as illustrated in Fig. 14(b). The angle of rotation is $\phi=\tan ^{-1}\left\{x_{T} / y_{T}\right\}$. In the new $(x, y, z)$ coordinate system, the transmitter location $\mathbf{T}$ is related to its coordinates in the old $\left(x^{\prime}, y^{\prime}, z^{\prime}\right)$ coordinate system by $\mathbf{T}=\mathbf{P}_{\phi} \mathbf{T}^{\prime}$ where $\mathbf{P}_{\phi}$ is the rotation matrix given by

$$
\mathbf{P}_{\phi}=\left[\begin{array}{ccc}
\cos \phi & -\sin \phi & 0 \\
\sin \phi & \cos \phi & 0 \\
0 & 0 & 1
\end{array}\right] .
$$

Similarly, $\mathbf{R}=\mathbf{P}_{\phi} \mathbf{R}^{\prime}$ and $\mathbf{S}=\mathbf{P}_{\phi} \mathbf{S}^{\prime}$.

Using simple geometric operations in the new coordinate system, the differential path length $\Delta$ and the grazing angle $\theta_{g}$ are given by

$$
\begin{aligned}
\Delta & =\sqrt{\left(z_{T}+z_{R}-2 z_{S}\right)^{2}+y_{T}^{2}}-\sqrt{y_{T}^{2}+\left(z_{T}-z_{R}\right)^{2}} \\
\theta_{g} & =\tan ^{-1}\left\{\frac{z_{T}+z_{R}-2 z_{S}}{y_{T}}\right\} .
\end{aligned}
$$

For most of the cases of practical interest, $y_{T} \gg$ $z_{T}, z_{R}, z_{S}$ so that (17) and (18) are well approximated by truncated Taylor series. Using the Taylor series approximations and the relationship $\tau=\Delta / c$ we

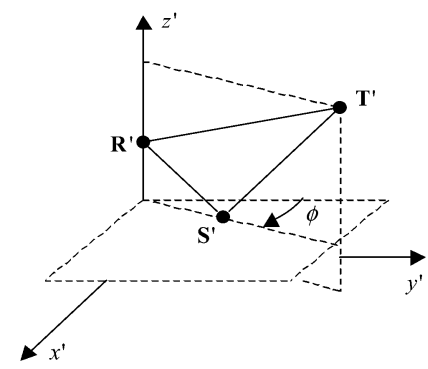

(a)

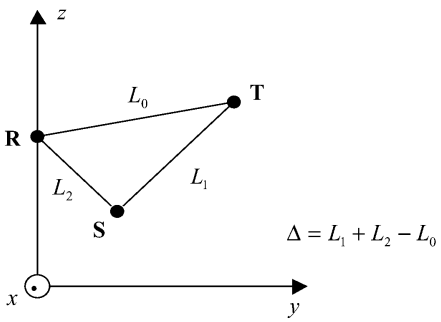

(b)

Fig. 14. Geometric details of multipath reflection. (a) Geometry of multipath reflection in south-east-up Cartesian coordinate system $\left(x^{\prime}, y^{\prime}, z^{\prime}\right)$ located at sea-level at latitude and longitude of receiver. (b) Geometry of same multipath reflection in rotated Cartesian coordinate system $(x, y . z)$.

obtain

$$
\begin{aligned}
\tau & \approx \frac{2\left(z_{T}-z_{S}\right)\left(z_{R}-z_{S}\right)}{c y_{T}} \\
\theta_{g} & \approx \frac{z_{T}+z_{R}-2 z_{S}}{y_{T}} .
\end{aligned}
$$

For dynamic channel behavior, the time derivatives of the spatial coordinates are computed. If the transmitter velocity vector is $\mathbf{v}_{T}^{\prime}=\left[\dot{x}_{T}^{\prime}, \dot{y}_{T}^{\prime}, \dot{z}_{T}^{\prime}\right]^{\mathrm{T}}$, then $\mathbf{v}_{T}=\left[\dot{x}_{T}, \dot{y}_{T}, \dot{z}_{T}\right]^{\mathrm{T}}$ is given by $\mathbf{v}_{T}=\mathbf{P}_{\phi} \mathbf{v}_{T}^{\prime}$. The corresponding changes in $\tau$ and $\theta_{g}$ are

$$
\begin{aligned}
& \dot{\tau}=-\frac{2\left(z_{T}-z_{S}\right)\left(z_{R}-z_{S}\right)}{c y_{T}^{2}} \dot{y}_{T}+\frac{2\left(z_{R}-s_{S}\right)}{c y_{T}} \dot{z}_{T} \\
& \dot{\theta}_{g}=-\frac{z_{T}+z_{R}-2 z_{S}}{y_{T}^{2}} \dot{y}_{T}+\frac{1}{y_{T}} \dot{z}_{T} .
\end{aligned}
$$

Again, for the cases of practical interest, $y_{T} \gg z_{T}, z_{R}, z_{S}$ so that $\dot{\theta}_{g} \approx 0$. Hence the changes in the reflections coefficients given by (11) and (12) are negligible. Changes is $\tau$ will also be small. But even small changes in $\tau$ will cause significant changes in the overall phase of the multipath reflection since the shift since the phase shift is $\omega_{c} \tau$ and the carrier frequencies are in the L-band $(1500 \mathrm{MHz})$ and lower S-band (2200 MHz).

\section{ACKNOWLEDGMENTS}

The authors acknowledge the help of Bob Jefferis at Edwards AFB and Gene Law at Pt. Mugu Naval Air Weapons Center with data reduction, interpretation, and sanity checks. 


\section{REFERENCES}

[1] Proakis, J. (2001)

Digital Communications (4th ed.).

New York: McGraw-Hill, 2001.

[2] Lee, W. C. Y. (1998)

Mobile Communications Engineering: Theory and

Applications (2nd ed.).

New York: McGraw-Hill, 1998.

[3] Lutz, E., Cygan, D., Dippold, M., Dolainsky, F., and Papke, W. (1991)

The land mobile satellite communication channel-Recording, statistics, and channel model. IEEE Transactions on Vehicular Technology, 40 (May 1991), 375-386.

[4] Vucetic, B., and Du, J. (1992)

Channel modeling and simulation in satellite mobile communication systems.

IEEE Journal on Selected Areas in Communications, 10, 8 (Oct. 1992), 1209-1218.

[5] Rice, M., Dye, R., and Welling, K. (2000)

Narrowband channel model for aeronautical telemetry. IEEE Transactions on Aerospace and Electronic Systems, 36, 4 (Oct. 2000), 1090-1098.

[6] Rappaport, T. (1996) Wireless Communications: Principles \& Practice. Upper Saddle River, NJ: Prentice-Hall, 1996.

[7] Rummler, W. (1979)

A new selective fading model: Application to propagation data.

Bell Systems Technical Journal, 58 (May-June 1979), 1037-1071.
[8] Parsons, J. D. (1994)

The Mobile Radio Propagation Channel.

New York: Wiley, 1994.

[9] Rice, M., de Gaston, D., Davis, A., German, G., and Bettwieser, C. (1999)

ARTM channel sounding results-An investigation of frequency selective fading on aeronautical telemetry channels.

In Proceedings of the International Telemetering Conference, Las Vegas, NV, Oct. 1999.

[10] Hayes, M. (1996) Statistical Digital Signal Processing and Modeling. New York: Wiley, 1996.

[11] Peterson, R., Ziemer, R., and Borth, D. (1995) Introduction to Spread Spectrum Communications. Englewood Cliffs, NJ: Prentice-Hall, 1995.

[12] Oppenheim, A., and Willsky, A. (1997) Signals \& Systems (2nd ed.). Upper Saddle River, NJ: Prentice-Hall, 1997.

[13] Balanis, C. (1989) Advanced Engineering Electromagnetics. New York: Wiley, 1989.

[14] Pritchard, W., Suyderhoud, H., and Nelson, R. (1993) Satellite Communication Systems Engineering. Englewood Cliffs, NJ: Prentice-Hall, 1993. 

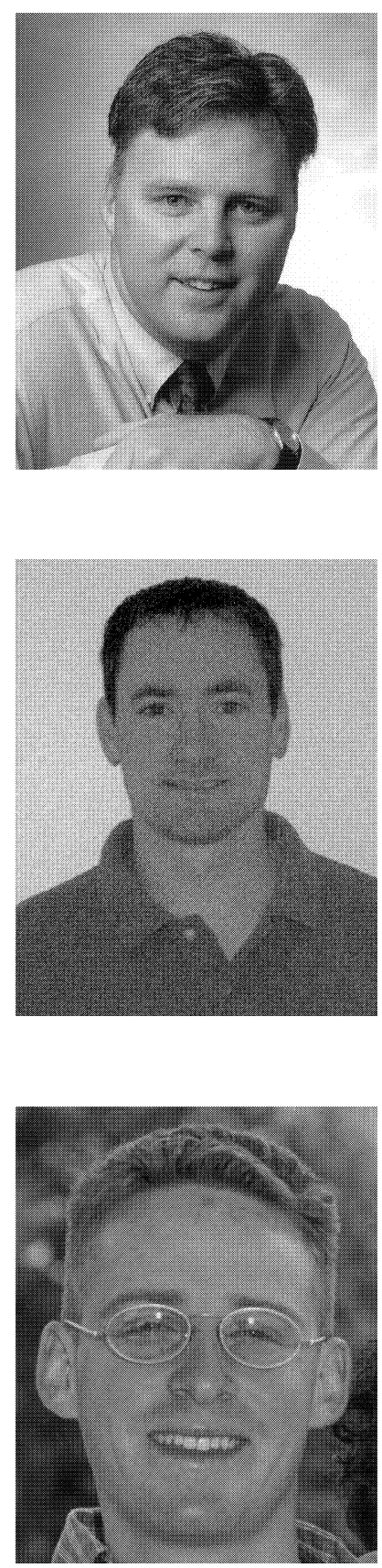

Michael Rice (M'82-SM'98) received a B.S.E.E. from Louisiana Tech University in 1987 and his Ph.D. from Georgia Tech in 1991. Dr. Rice was with Digital Transmission Systems, Inc. in Atlanta and joined the faculty at Brigham Young University in 1991 where he is currently the Jim Abrams and Anita Schiller Professor in the Department of Electrical and Computer Engineering. Professor Rice was a NASA/ASEE summer faculty fellow at the Jet Propulsion Laboratory during 1994 and 1995 where he worked on land mobile satellite systems. During the 1999-2000 academic year, Professor Rice was a visiting scholar at the Communication Systems and Signal Processing Institute at San Diego State University.

Professor Rice's research interests are in the area of digital communication theory and error control coding with a special interest in applications to telemetering and software radio design. He has been a consultant to both government and industry on telemetry related issues. He is a member of the IEEE Communications Society and was chair of the Utah Section of IEEE from 1997 to 1999 and IEEE Region 6 Student Activities Coordinator from 2000 to 2002. He is currently chair of the Signal Processing and Communications Society Chapter of the Utah Section.

Adam Davis is from Wadesboro, NC and received his B.S. in physics and M.S. in electrical engineering from Brigham Young Univeristy in 1997 and 2001, repectively.

While at BYU, he worked in the BYU Telemetry Laboratory on modeling the aeronautical telemetry channel. He currently works for the IEWS Division of BAE Systems, North America in Hudson, NH, where his responsibilities include the development of software radio technolgy. His technical interests include communication theory and computer programing. He enjoys long-distance running and regularly participates in 5 and $10 \mathrm{~K}$ races and marathons.

Christian Bettwieser received a B.S.E.E. from Brigham Young University in 2000. At present, he is employed at Argon Engineering as a software engineer while completing his master's degree at Brigham Young University. His interests are on software radio techniques. Christian is a member of Tau Beta Pi and Eta Kappa Nu. He also is an avid potter and cellist, having played in the Utah Valley Youth Symphony. 